\title{
Unifying Sustainable Development Goals: How Cultural and Creative Engagement are the Missing Links to Advancement
}

\author{
By Jayanna Killingsworth ${ }^{1}$
}

\begin{abstract}
The United Nations Conference on Trade and Development (UNCTAD) named 2021 as the Year of the Creative Economy. While symbolically significant, the designation does a disservice to Cultural and Creative Industries (CCIs) by dismissing their intrinsic and societal value. It also perpetuates a myth that these industries have economic viability as their sole contribution for advancing the United Nations Sustainable Development Goals (UN SDGs). By triangulating psychological underpinnings, established methodologies, and recommendations from leading organizations this paper challenges the contemporary siloed assumption of CCIs advancement through commodification alone. It has been shown that exposure to culture and creativity is vital for psychological well-being in individuals and society, while simultaneously eliciting abilities to garner new perspectives towards issues such as the climate crisis. These characteristics are fundamental for advancing sustainable development at broader levels and there are numerous underpinnings within the UN SDGs that corroborate the need to move beyond antiquated ways of doing and thinking. By looking at recommendations through the lenses of well-being and new perspectives, it is possible to create a roadmap that strengthens the 2030 Agenda by utilizing intrinsic values and practices from the CCIs.
\end{abstract}

Keywords: Sustainable, Development, Cultural, Creative, Well-Being, United Nations, Industries, Systems

\section{Introduction}

Sustainability Science has made considerable strides in establishing evidence of the historical shifts in the Earth's climate and quantified models of the contemporary anthropogenic effects that are exacerbating the climate crisis (Karl et al., 2009; Schneider et. al.., 2010). These models identify the complex interplay between greenhouse gas (GHG) emissions, global warming, rising sea levels, shoreline erosion, regional conflicts, increased severity of storms, biodiversity loss, depletion of indigenous culture, broadening inequality, glacial melt, land degradation, migration of insects, and water scarcity (Karl et al., 2009; Jerneck et al., 2010; United Nations Environment Program, 2019; World Economic Forum, 2021). As a result of the findings by continued Sustainability Science research, a consensus has emerged; mitigation and adaptation, which entail co-designed inter and transdisciplinary approaches, are necessary to curb the devastating results that the models indicate (Karl et al., 2009; Jerneck et al., 2010; Shrivastava et al., 2020; OECD, 2020a). In the wake of this consensus, various accords of intent emerged, including the Paris Agreement, Earth Charter, United Nations Sustainable Development Goals (UN SDGs), and the World Economic Forums' Great Reset.

However, even with these accords, there has still been minimal action taken by the leading 
industrialized countries, resulting in the need for more extreme responses to happen in a shorter amount of time (Shrivastava et al., 2020; World Economic Forum, 2021). One contributing factor in the lack of action is that most information and dissemination campaigns focus wholly on quantifiable data, with merely minor qualitative reinforcements via Social Sciences, Humanities, and the Arts (Yusoff \& Gabrys, 2011; Shrivastava et al., 2020; OECD, 2020a). The dismissal of more qualitative approaches signals the continual unstated institutional notion that initiatives without precise measurements and mathematical models are irrelevant or somehow less legitimate (Meadows, n.d.; Maxwell, 2018). This is counterintuitive to the multi-faceted nature of human perceptions, understanding, Traditional Knowledge (TK), and dissemination practices. Individual and group perceptions are directly linked to factors such as psychological, surrounding culture, and political understandings (DuPraw \& Axner, 1997; Roser-Renouf et al., 2009). The amalgamation of how we interact with each other, whether through art, dialogue or educational practices, encompasses more complexity and diversification than neither quantified nor qualitative data can represent independently.

Moreover, when individuals are unable to relate to something such as the climate crisis, view it as institutional hype or a distant concern, then their emotions and ability for empathy tend to be unattached and immediate action does not occur (Van der Linden et al., 2015; Eisenstein, 2018; Greco, 2019). For mitigation and adaptive practices to take root, all global citizens need to understand and communicate through various mediums how climate change affects them. This ability to create personal and social relevance will aid the enrollment of more diverse actors and institutions in developing bottom-up community strategies as well as reimagining of the current narrative for future policy directives with broader systemic efforts (Meadows et al., 2004; Eisenstein, 2018). As the matrix in Figure 1 illustrates, these endeavors cannot be done by relying on quantified data alone because that does not provide a fully systemic picture of the social dynamics occurring on the ground.

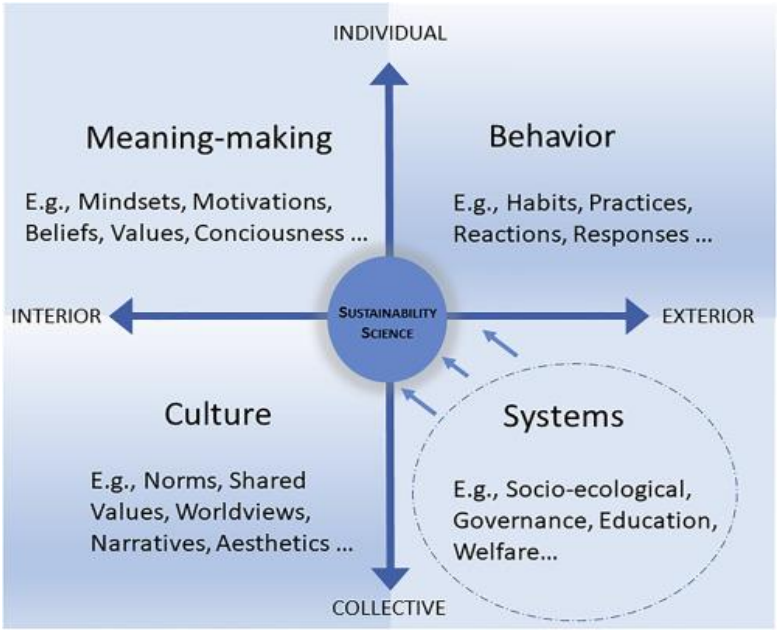

Figure 1: Matrix showing possible integration of Sustainability Science with both quantitative and qualitative perspectives Source: Retrieved from Shrivastava et al. (2020), Transforming Sustainability Science to Generate Positive Social and Environmental Change Globally. https://doi.org/10.1016/j.oneear.2020.04.010 
There are a multitude of local initiatives around the world who are incorporating creative approaches to tackle local and regional concerns related to the climate crisis. Some examples include Tunisia's cultural policy regulations, the Art for Change project in Lisbon, Portugal, and Sweden's Collaborative Cultural Model (UNESCO, 2018; Bentz, 2020). Even with localized initiatives like these, there are still no normative frameworks in circulation to ensure that the climate crisis is being considered from such a holistic perspective (Meadows et al., 2004; Dyer, 2007; UNESCO, 2018; Shrivastava et al., 2020). Based on this premise, this paper focuses on how Cultural and Creative Industries (CCIs) can serve as a qualitative way to advance sustainable development. It is imperative to go beyond the economic valuation of the CCIs as an essential step in understanding the societal worth of the industries. At the heart of the CCIs, there is an intrinsic value to provide mediums and sources that elicit well-being with the simultaneous potential to garner new perspectives in individuals and groups. Through a discourse analysis of the current narrative approaches of the UN SDGs, it is possible to highlight certain gaps where cultural and creative perspectives are needed. It is through these steps that allow the culmination of initial recommendations from Cultural and Creative Education (CCE), the United Nations Educational, Scientific and Cultural Organization (UNESCO), and the Voices of Culture, among others, to illustrate that real change could happen if an expanded effort were placed on incorporating more holistic practices into the SDGs. This examination of language in key policy documents reveals that CCIs and CCEs are largely omitted from the invitation to tackle the climate crisis. This oversight is a grave missed opportunity to engage cultural expression as a way to galvanize the very actors, communities, and institutions that may prove crucial to the success of this cause.

\section{Beyond Quantifiable Worth}

CCIs encompass numerous sectors such as museums, universities, galleries, and heritage sites; as well as visual, performing, and digital arts, interior design, furnishings, crafts, media and publishing, and architecture (Eisenberg et al., 2006; Schlesinger, 2017; United Nations Conference on Trade And Development, 2019). In the past few decades, there has been a rise in the concept of Cultural Economics with various incantations, definitions, and parameters utilized to determine and distinguish what constitutes culture and creativity (Weldon, 1972; Searle, 2017). Through the varied perspectives developed, a common denominator is that quantifying these sectors and sub-sectors is complicated because of their intangible values and intrinsic ties with TK (Eisenberg et al., 2006; Searle, 2017). Even with the precarious nature of determining factors, in 2018, the combined global economic worth was estimated at 2.25 trillion USD (UNESCO, 2018). The following year the United Nations Conference on Trade and Development (UNCTAD) declared 2021 as the Year of the Creative Economy (2019). The main direction behind the establishment of this declaration is to facilitate an overall goal that "...generates economic information through a trade lens, to understand trends and promote data-led understanding of trade in creative goods and services, intellectual property, ideas and imagination" (United Nations Conference on Trade And Development, n.d.). This goal aligns with the same unstated paradigm among policymakers, governments, and organizations that non-quantifiable value is irrelevant (Maxwell, 2018). Regardless of the 
calculations attempted, global value assessments, and auction prices collected, the intrinsic and societal enrichment associated with cultural and creative practices can never be reliably remunerated (Crosswick, 2006; Yusoff \& Gabrys, 2011; Schlesinger, 2017; Searle, 2017). It has become even more apparent over the last year.

A notable point is that the UN declaration occurred just months before the global pandemic. Throughout most of 2020 and well into 2021, the Covid-19 pandemic has eliminated much of the CCIs physical engagement capabilities and earning potential. In mid-2020, the StraitsTime Sunday edition from Singapore conducted a poll in which 71\% of the 1000 adults surveyed declared artists non-essential workers (Tai, 2020). While this is a small sampling compared to the overall pandemic impact, this article was reproduced in many industrialized countries and was seen as adding insult to injury to the percentage of the workforce within the CCIs, as shown in Figure 2. It also became a contradictory point when one looks at the increase of people worldwide utilizing streaming services, participating in online workshops for creative outlets, and municipalities engaging in artistically rendered public service campaigns (OECD, 2020b; Radermecker, 2021). Although this activity has maintained and even increased revenue for certain supply manufacturers and tech companies, the underlying message is more profound than yearly earnings; human beings need forms of creative expression to deal with the uncertainty of the times (Chambon, 2008; Radermecker, 2021). This pandemic-related example illustrates the deceptive nature of using economic measures to determine value, thus highlighting that the Year of the Creative Economy designation does a disservice to CCIs by dismissing their intrinsic value.

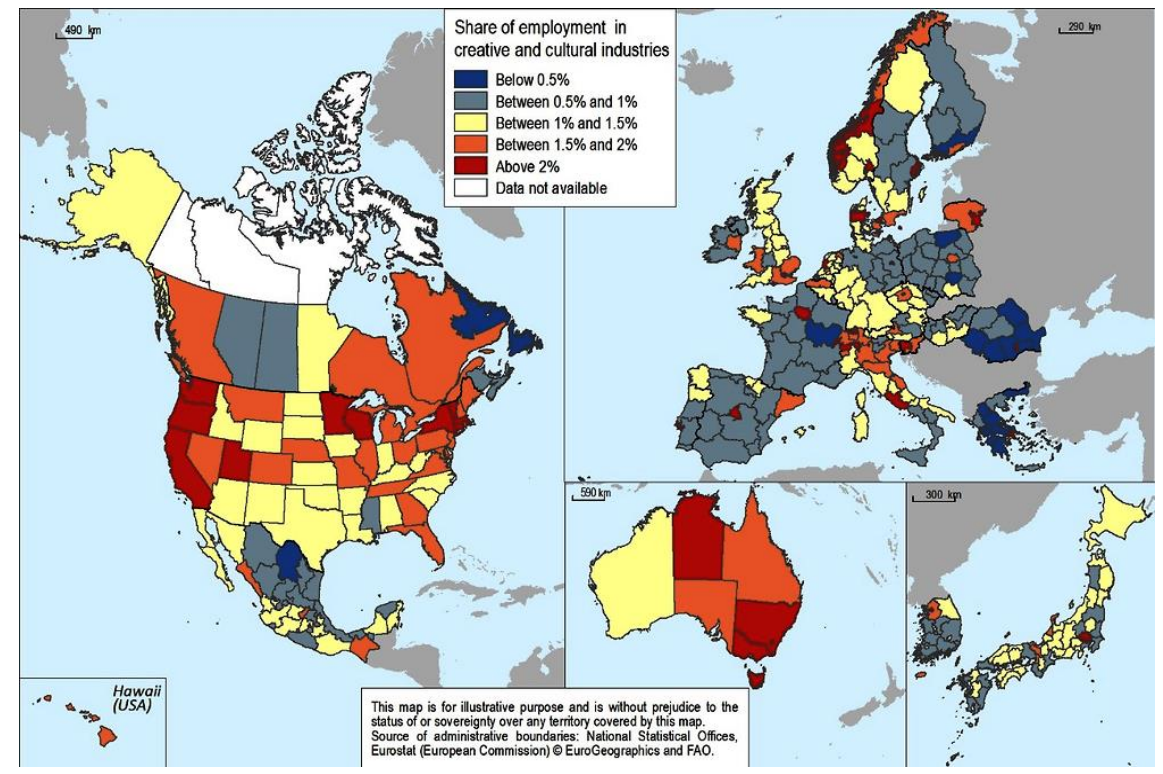

Figure 2: Share of employment in creative and cultural sectors, TL2 regions in 2017 or latest available year for OECD countries

Source: Retrieved from OECD (2020b), Culture Shock: COVID-19 And The Cultural And Creative Sectors. bttps: / www.oecd.org/coronavirus/policy-responses/culture-shock-covid-19-and-the-cultural-and-creative-sectors$\underline{08 d a 9 e 0 e l}$ 
The Creative Economy designation also perpetuates a myth that these industries have economic viability as their sole contribution to addressing the climate crisis. It is necessary to see the societal fallout and disruptions of the pandemic as a warning of what could unfold if the lagging efforts of the climate crisis continue without holistic interventions (Dyer, 2007; Rettner, 2021). What should be stressed is that the need to find meaning and sources of inspiration during times of uncertainty is not determined by status or location; people from all socio-economic backgrounds have found significance in the physical act of creating (Chambon, 2008; Higgs, 2008). Historically, various forms of artistic practices have defined cultures across the world, spurred revolutions, invoked emotions, inspired scientific discoveries, assisted with social adaptations, bridged innovation practices with networks, and provided people with an aesthetic representation of their existence for centuries (Dewey, 1980; Jirousek, 1995; Higgs, 2008). From Aboriginal rock paintings, Egyptian monuments, Greek literature, Aztec figurines, Japanese woodblock prints, and illuminated manuscripts, to the Futurists, Bauhaus and Fluxus imaginings, and into the contemporary movement of the artivist, creative outlets have continuously provided a source of refuge, protest, and inspiration through the ages. In the face of the climate crisis, many are again turning to artistic outlets to cope and express social injustices and represent the non-human voices that cannot speak for themselves (Yusoff \& Gabrys, 2011). Unfortunately, in the landscape of mass consumption, the depths of creating for its own sake have been overshadowed by waves of disposable designs to be consumed instead of revered.

\section{Creativity for Well-Being}

Those working within the multiple sectors of the CCIs have long known the positive effects of exposure to creativity. Furthermore, these sectors have strived to provide opportunities for public engagements, often noting that as core missions, but it is not enough for this understanding to stay isolated within the sector niches. Contemporarily, there is an increasing amount of medical research validating that exposure to various forms of creativity has positive effects on the overall well-being of individuals (Fancourt \& Finn, 2019). The benefits described here are based on both physical and psychological impacts. The physical responses associated with increased exposure to cultural and creative practices include reducing hormonal markers of stress, lowering blood pressure, and decreasing the physiological effects of pain (Straicoff, 2004; Stuckey \& Nobel, 2010; Rollins, 2015). These positive physical responses to exposure are significant for aiding individuals' sense of well-being (Fancourt \& Finn, 2019; OECD, 2020b). Beyond having positive effects against physical ailments, there are also numerous beneficial psychological responses to creative endeavors.

These benefits include elevating a sense of comfort, reducing the psychological issues associated with pain, increasing focus, heightening empathy, decreasing stress and anxiety, and triggering positive memories (Straicoff, 2004; Stuckey \& Nobel, 2010; Rollins, 2015). As Jung (1968) noted, "Humans have a symbol-making propensity and when that is intertwined with an object or form it then has the capability to carry great psychological value" (p. 257). Through an increased psychological sense of well-being, individuals can move beyond the functional limitations of only surviving and into a space to explore new 
ways of thinking, being, and doing (Higgs, 2008; Fancourt \& Finn, 2019). Through these exploration sources, both individuals and groups can begin looking at the world with a renewed set of attributes.

Creative-based attributes that stem from broadening the sense of psychological well-being include awareness, compassion, imagination, and enchantment (Eisner, 2008; Galafassi, 2018; Americans for the Arts, 2018). Collectively, creative forms of exploration can necessitate the spontaneity of initiatives, healing through imagination, and co-developed action that cannot be predetermined in a boardroom reviewing data or combing through peer-reviewed articles (Yusoff \& Gabrys, 2011; Seeley \& Thornhill, 2014; Galafassi, 2018; Shrivastava et al., 2020). Additionally, these collective effects provide an element of social cohesion that occurs when groups participate in creative endeavors. The often informal nature and lack of hierarchical labels that occur during group-based artistic projects allow for bridging interactions from diverse backgrounds to occur (Lee, 2013; Vermeulen \& Maas, 2021). It has also been found that members of these groups can develop a bond through their shared experience and relevance of the project they are participating in (Lee, 2013). The importance of social cohesion through social bridging and bonding should not be underestimated elements for developing a united stance against the climate crisis and can be used to reinforce actions pertaining to sustainable frameworks.

\section{Current Sustainable Development Framework}

The UN SDGs 2030 Agenda is the most notable and accepted framework in circulation. Thanks in part to creative design decisions, the brightly colored and easy-todecipher goals are becoming ubiquitous to the generalized concept of sustainable development. Within the Agenda, there are 17 goals, 169 targets, and 247 indicators with overarching objectives for national, regional, and global levels (United Nations Department of Economic and Social Affairs, n.d.). They were unveiled in 2015 as an extension of the original eight Millennium Development Goals (MDG) to bridge the societal and environmental gaps found in the original framework (Norström et al., 2014; Swain, 2018; Kroll et al., 2019). Even though the focus of the MDG has been expanded upon, there is contention regarding the SDGs being too ambiguous, non-binding, and remaining in line with Neoliberalism as a means to an end without addressing that these same measures are the root causes of the anthropogenic climate crisis (Yusoff \& Gabrys, 2011; Eisenmenger et al., 2020; Kopnina, 2020; Shrivastava et al., 2020). This study analyzes discourse used throughout the SDGs to better understand the existing narrative relating to the CCIs.

An initial keyword search through the SDGs combined goals, targets, and indicators found a total of 10 places where the terms Culture, Creativity, and Well-Being were explicitly used; whereas the terms Economic, Funding, and Productivity were used a total of 38 times, as shown in Table 1. This initial analysis reinforces the disparage between the perceived importance of financial development versus holistic development. Although there are two instances where a keyword for each of the searches was used within a numbered goal, SDG 3: Good Health and Well-Being and SDG 8: Decent Work and Economic Growth; the remainder of the time, the terms were relegated to the targets and indicators with the term Economic far exceeding all other keywords combined. 
Table 1: Initial Keyword Analysis of Six Terms in the SDGs, Appearing in Order of Occurrence

\begin{tabular}{|c|c|c|}
\hline KEYWORD & OCCURRENCE & LOCATION \\
\hline Economic & 31 & $\begin{array}{l}\text { 1.4(x2), 1.5(x4), 1.5.2, 5.2(x2), 5.5(x2), 8, 8.1, 8.2, 8.4(x2), } \\
9.1(\mathrm{x} 2), 10.2(\mathrm{x} 2), 10.6,11 . \mathrm{a}, 11.5(\mathrm{x} 2), 11.5 .2,12 . \mathrm{b} .1,14.7, \\
\text { 15.9.1, 15.a.1, 15.b.1, 17.2.1 }\end{array}$ \\
\hline Culture & 6 & $4.7,8.9,11.4,11.4 .1(\mathrm{x} 2), 12 . \mathrm{b}$ \\
\hline Productivity & 4 & $2.3(\mathrm{x} 2), 2.4,8.2$ \\
\hline Funding & 3 & $11.4 .4,17.7 .1,17.18 .3$ \\
\hline Well-Being & 3 & $3,4.2 .1,9.1(\mathrm{x} 2)$ \\
\hline Creativity & 1 & 8.3 \\
\hline
\end{tabular}

Note: Keyword search conducted using the Danish Institute for Human Rights SDGs guide (n.d.). Blue indicates the first search that focused on terms associated with this theory. Yellow indicates the terms associated with monetary evaluations as a determination for development, with the exclusion of two instances the reference macroeconomics. Multiple references within the same target or indicator are noted within parentheses.

With the minimal inclusion of culture, creativity, and well-being being found, there are numerous opportunities to expand the breadth and capabilities of the SDGs to incorporate these socially relevant areas (Nunes et al., 2016; UNESCO, 2017). Especially since one stand-out element that all 17 goals share is that, in practice, each goal relies on a cumulative effort of the others to turn trade-offs into synergies and act with new pathways of knowledge (Kroll et al., 2019; Shrivastava et al., 2020). As Table 1 alludes to, there are numerous underpinnings throughout the phrasing of goals, targets, and indicators that corroborate the need to move beyond antiquated ways of doing and thinking.

\section{Integration of CCIs and SDGs}

The notion of developing new pathways of knowledge through creativity is not a linear process and has no easily definable methodology or simplified process (Chambon, 2008). It is precisely that non-linear nature that allows for the needed reflexivity to integrate into each unique situation (Seeley \& Thornhill, 2014; Galafassi, 2018; Shrivastava et al., 2020). Open-ended reflexivity has an imperative role to play in what is socially determined to be of value (Meadows, n.d.; Chambon, 2008). This is particularly important for the future of sustainable development advancements (Meadows et al., 2004). If economic factors are the only drivers of the concept of development, the inherent complexity of anthropogenic meaning-making is lost to business advertisements, consumption trends, and disposable design (Galafassi, 2018). Moreover, it leaves no room for the richness, complexity, and interconnected dependencies of non-human existence (Eisenstein, 2018). Without an appreciation of and even reverence for the natural world that is often found in many genres of creative expression, how can we expect the changes required to alter the impact of the anthropogenic effect?

Culture and creativity do not exist within a vacuum, and beyond visual sharing, they are often disseminated through a range of dialogue and education. Informally, examples of this within TK include customary adornment, living practices, and generational wisdom passed down verbally and experientially. Formal examples can include academic works and museum exhibitions. Collard and Witte (2015) have noted prominent reports such as the Seoul 
Agenda, Culture 21, and Article 31 of the UN Convention on the Rights of the Child that have been independently commissioned over the years to expand CCE functions (p. 3). At the same time, organizations such as Americans for the Arts (2018) have focused on American society's perceptions about the arts. Additional recommendations for expanding CCIs influence on the SDGs include ongoing reports from UNESCO (2018) and Voices of Culture (2021) and a myriad of independent research done through various organizations and nonprofit entities, some of which are referenced throughout this paper. A commonality among all of these reports acknowledges, to varying degrees, that an increase in creative interpretations, cultural agency, and artistic ways of doing serve as drivers for eliciting positive change. Many also provide recommendations for expanding the influence of the CCIs and CCE. Most of these recommendations include the explicit inclusion of CCIs and CCE within the existing SDGs framework as a matter of great importance (Collard \& Witte, 2015; UNESCO; 2018; Voices of Culture, 2021). In totality, these reports serve as conduits to illuminate the importance of the CCIs sectors beyond just economic viability. After an initial review of the various recommendations, the cumulative list found in Figure 3 is proposed as a baseline minimum of what efforts need to be enacted.

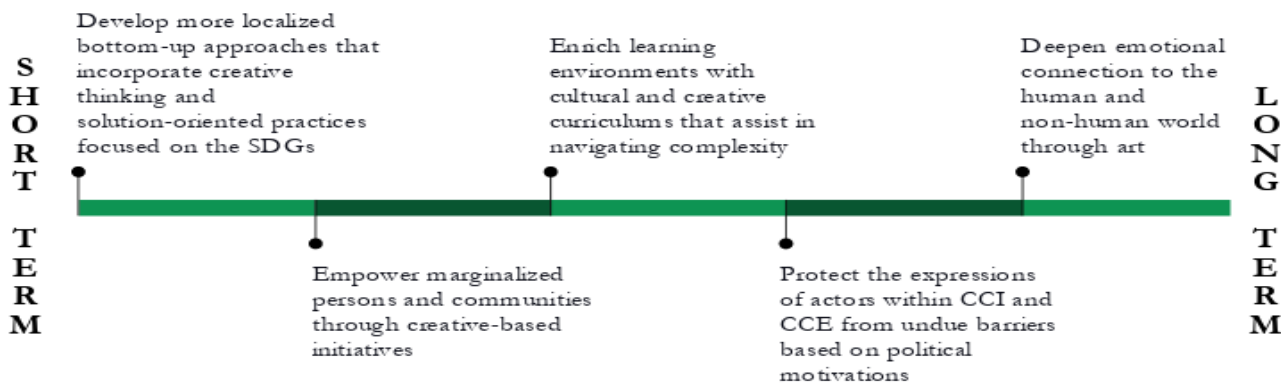

Figure 3: Cumulative list to advance CCIs/CCEs within the SDGs.

Source: Compiled from, DuPraw \& Axner (1997); Meadows (1999); Meadows et al. (2004); Crossick (2006); Dyer (2007); Chambon (2008); Collard \& Witte (2015); United Nations (2016); Milkoreit (2017); Americans for the Arts (2018); Eisenstein (2018); Galafassi et al. (2018); UNESCO (2018); V oices of Culture (2021).

The short and long term incorporations of these five initial recommendations could democratize much of the local and regional decision-making process and allows individuals and societies to lead themselves in the active participation of the planet's regeneration and drive new pathways of knowledge (Meadows, n.d.; Meadows, 1999; Meadows et al., 2004; Crossick, 2006; Galafassi et al.., 2018; Maxwell, 2018; UNESCO, 2018; Voices of Culture, 2021). It can also serve as a foundation for extending stakeholder engagements with practices that incorporate imagination, visionings, and story-telling for the sake of a holistic approach to normative sustainable development action.

\section{Future Directions}

This review of key global directives for mitigating climate change to examine the potential role of CCIs and CCEs in catalyzing change places the shortcomings of current policy in stark relief. A roadmap for developing a more holistic framework, integrating the 
intrinsic values and scopes that CCIs and CCEs can contribute to the climate crisis, is needed to ameliorate the current state of affairs and enroll crucial actors and institutions that are, in effect, sidelined at the very moment they are needed the most. Within this context, there are still plenty of opportunities to embrace emergent findings, incorporate knowledge from leaders and experts in the various sectors, and illustrate the complexity of the numerous systems involved (Sevaldson, n.d.; Eriksson \& Kovalainen, 2008; Bartlett \& Vavrus, 2017). To further define systemic integration requires continued rigor to uncover more academic literature and non-academic sources that provide examples of practice, successful integration projects, and critical responses. Ensuring there is equity within this approach, a concerted effort of the disparages in definitions of sustainable development and access between the Global North and Global South and the nuanced socio-political underpinnings that have delayed the progress of holistic approaches in addressing the climate crisis. Additionally, it is of equal importance that this research also considers how the activities of the CCIs are directly affecting the climate crisis through its cycles of extractive production and exploitative consumption. For this, understanding the underlying driving factors of organizational behaviors, more than human effects, supply chain management, gaps in efforts, and power dynamics will lead to rectifying possible hypocrisies and provide a deeper context for this argument.

\section{Conclusion}

There is no established roadmap for the necessary changes required to curb the climate crisis, nor are there any simple solutions to the complexity of the issues we face (Meadows et al., 2004). Through highlighting the shortcomings of contemporary approaches, it has become apparent that relying on the same patterns that created these problems will not be sufficient to solve them. Since we have defined the parameters that have led to excessive global destruction based on economic prosperity and unlimited growth, it is equally possible that we can redefine those boundaries by incorporating the relevance of creative expression to alter the future trajectory of sustainable development. Ultimately, art, culture, and economic principles are all human-made constructs that can be reinvented and redefined for the good of social and ecological wellness (Meadows, n.d.; Gay, 2020). With the UN SDGs' foundational framework, there is a wealth of inspiration for such collective efforts (Wapner \& Elver, 2016). While not exhaustive, this paper's defined set of recommendations offers a starting point for reimagining these constructs if we are willing to cultivate action that combines our minds and hearts (Esienstein, 2018; Waddell, 2015). Just imagine what the world could be if we acted with wonder, enchantment, reverence, and empathy.

\section{References}

Americans for the Arts. (2018). Americans speak out about the arts in 2018: An in-depth look at perceptions and attitudes about the arts in America. https://www.americansforthearts.org/sites/default/files/Public \%20Opinion $\% 20$ National $\% 202018 \% 20$ Report.pdf

Bartlett, L., and Vavrus, F. (2017). Comparative case studies: An innovative approach. Nordic Journal of Comparative and International Education, 1(1), 5-17. https://www.researchgate.net/publication $\angle 320011725$ Comparative Case Studies An Innovative Approach 
Bentz, J. (2020). Learning about climate change in, with and through art. Climatic Change, 162, 1595-1612. https://doi.org/10.1007/s10584-020-02804-4

Chambon, A. (2008). 49 Social work and the arts: Critical imagination. In J. G. Knowles \& A. L. Cole Handbook of the arts in qualitative research: Perspectives, methodologies, examples, and issues. Sage.

Crossick, G. (May 31, 2006). Knowledge transfer without widgets: The challenges of the creative economy. The Royal Society of Arts in Leeds. [Lecture]. https://theplayethic.typepad.com/files/crossick knowledge-transfer-without-widgets.pdf

Collard, P. and Witte, R. (2015). Creative Alliances for Europe. https://www.creativitycultureeducation.org//wpcontent/uploads/2018/10/NAE-Final-Report.pdf

Danish Institute for Human Rights. (n.d.). Goals, targets, and indicators. https://sdg.humanrights.dk/en/goalsand-targets

Dewey, J. (1980). Art as experience. Perigee.

DuPraw, M.E. and Axner, M. (1997). Working on common cross-cultural communication challenges. In book: Toward a more perfect union in the age of diversity. A guide for building stronger communities through public dialogue. Topsfield Foundation. https://www.researchgate.net/publication/269168852 Working on common cross-cultural challenges

Dyer, A. (2007). Inspiration, enchantment and a sense of wonder... Can a new paradigm in education bring nature and culture together again? International Journal of Heritage Studies, 13(4/5), 393-404. https://doi.org/10.1080/13527250701351106

Eriksson, P., and Kovalainen, A. (2008). Qualitative methods in business research. Sage.

Eisenberg, C., Gerlach, R., and Handke, C. (Eds.). (2006). Cultural industries: The british experience in international perspective. Humboldt University Berlin. [Online]. https://edoc.huberlin.de/bitstream/handle/18452/18524/culturalindustries.pdf?sequence $=1$

Eisenstein, C. (2018). Climate- $A$ new story. North Atlantic Books.

Eisner, E. (2008). 1 Art and knowledge. In J. G. Knowles \& A. L. Cole Handbook of the arts in qualitative research: Perspectives, methodologies, examples, and issues. Sage.

Eisenmenger, N., Pichler, M., Krenmayr, N., Dominik Noll, Plank, B., Schalmann, E., Wandl, MT., and Gingrich, S. (2020). The sustainable development goals prioritize economic growth over sustainable resource use: A critical reflection on the sdgs from a socio-ecological perspective. Sustain Sci 15, 1101-1110. https://doi.org/10.1007/s11625-020-00813-x

Fancourt, D. and Finn, S. (2019). What is the evidence on the role of the arts in improving health and wellbeing? A scoping review. World Health Organization- Health evidence network synthesis report 67. https://www.euro.who.int/en/publications/abstracts/what-is-the-evidence-on-the-role-of-thearts-in-improving-health-and-well-being-a-scoping-review-2019

Galafassi, D., Tàbara, J. D., and Heras, M. (2018). Restoring our senses, restoring the earth. Fostering imaginative capacities through the arts for envisioning climate transformations. Elementa Science of the Anthropocene, 6(1), 69. http://doi.org/10.1525/elementa.330

Gay, G. (November 4, 2020). Conversation with Dr. Geneva Gay. Prescott College. [Zoom forum].

Greco, C.J. (May, 2019). What's wrong with the way we communicate climate change? Environmental and Energy Study Institute. $\quad$ https://www.eesi.org/articles/view/whats-wrong-with-the-way-we-communicateclimate-change

Higgs, G. (2008). 46 Psychology: Knowing the self through arts. In J. G. Knowles \& A. L. Cole Handbook of the arts in qualitative research: Perspectives, methodologies, examples, and issues. Sage.

Jirousek, C. (1995). Art, design, and visual thinking. The evolution of art in the modern era. http://char.txa.cornell.edu/ART/introart.htm

Jerneck, A., Olsson, L., Ness, B., Anderberg, S., Baier, M., Clark, E., Hickler, T., Hornborg, A., Kronsell, A., Lövbrand, E., and Persson, J. (2011). Structuring sustainability science. Sustainability Science, (6)6982. https://doi.org/10.1007/s11625-010-0117-x

Jung, C. (Eds.). (1968) Man and his symbols. USA. Dell.

Karl, T. R., Melillo, J. M., and Peterson, T. C. (Eds.). (2009). Global Climate Change Impacts in the United States. Cambridge University Press.

Kopnina, H. (2020). Education for the future? Critical evaluation of education for sustainable development goals. The Journal of Environmental Education. 51(1), 1-12. http://dx.doi.org/10.1080/00958964.2019.1710444

Kroll, C., Warchold, A. and Pradhan, P. (2019). Sustainable development goals (SDGs): Are we successful in turning trade-offs into synergies?. Palgrave Commun (5)140 https://doi.org/10.1057/s41599-019-0335-5 
Lee, D. (2013). How the Arts Generate Social Capital to Foster Intergroup Social Cohesion. The Journal of Arts Management, Law, and Society, 43, 17-4. https://doi.org/10.1080/10632921.2012.761167

Maxwell, J. (2018). The value of qualitative inquiry for public policy. Qualitative Inquiry. https://www.researchgate.net/publication/326408499 The Value of Qualitative Inquiry for P ublic Policy

Meadows, D. (n.d.) Dancing with systems. https://donellameadows.org/archives/dancing-with-systems/

Meadows, D. (1999). Leverage points: Places to intervene in a system. The Sustainability Institute.

Meadows, D., Randers, J., and Meadows, D. (2004). Limits to growth: The 30-Year update. Chelsea Green.

Milkoreit, M. (2017). Imaginary politics: Climate change and making the future. Elementa Science and the Anthrocene, (5),62. DOI: https://doi.org/10.1525/elementa.249

Norström, A. V., A. Dannenberg, G. McCarney, M. Milkoreit, F. Diekert, G. Engström, R. Fishman, J. Gars, E. Kyriakopoulou, V. Manoussi, K. Meng, M. Metian, M. Sanctuary, M. Schlüter, M. Schoon, L. Schultz, and M. Sjöstedt. (2014). Three necessary conditions for establishing effective sustainable development goals in the anthropocene. Ecology and Society 19(3), 8. http://dx.doi.org/10.5751/ES$\underline{06602-190308}$

Nunes, A., Lee, K., and O'Riordan, T. (2016). The importance of an integrating framework for achieving the sustainable development goals: The example of health and well-being. BMJ Global Health. https://gh.bmj.com/content/1/3/e000068

OECD. (June 2020a). Addressing societal challenges using transdisciplinary research. OECD science, technology and industry policy paper, No 88. https://www.oecd-ilibrary.org/science-and-technology/addressingsocietal-challenges-using-transdisciplinary-research $0 \mathrm{ca} 0 \mathrm{ca} 45$-en

OECD. (September 2020b). Culture shock: COVID-19 and the cultural and creative sectors. OECD Policy Responses to Coronavirus (COVID-19). https://www.oecd.org/coronavirus/policy-responses/cultureshock-covid-19-and-the-cultural-and-creative-sectors-08da9e0e/

Radermecker, AS.V. (2021). Art and culture in the COVID-19 era: for a consumer-oriented approach. SN Business \& Economics 1(4), https://doi.org/10.1007/s43546-020-00003-y

Rettner, R. (May 20, 2021). Jane Goodall says humanity's 'disrespect of the natural world' brought on the pandemic. Live Science. https://www.livescience.com/jane-goodall-templeton-prize-sustainabilitynature.html

Rollins, J. (2015). Arts, health, and wellness. Arts \& America: Arts, Culture, and the Future of America's Communities. https://www.americansforthearts.org/sites/default/files/Arts\%26America_HealthWellness.pdf

Roser-Renouf, C., Maibach, E. W., and Leiserowitz, A. (2009). Global Warming's Six Americas: An Audience Segmentation Analysis. https://www.researchgate.net/publication/253113477 Global Warming's Six Americas An Audience Segmentation Analysis Invited

Schlesinger, P. (2017). The creative economy: Invention of a global orthodoxy. Innovation: The European Journal of Social Science Research, 30(1), 73-90, https://doi.org/10.1080/13511610.2016.1201651

Schneider, S. H., Rosencranz, A., Mastrandrea, M. D., and Kuntz-Duriseti, K. (2010). Climate change science and policy. Island Press.

Searle, N. C. (2017). Cultural economics, innovation and intellectual property. The Routledge Handbook of Global Cultural Policy https://www.routledgehandbooks.com/doi/10.4324/9781315718408.ch3

Seeley, C., and Thornhill, E. (2014). Artful organizations. http://www.wildmargins.com/Home files $\angle$ Artful $\% 20$ Organisation $\% 20$ Report Online-Edit.pdf

Seidel, S., Kruse, L. C., Székely, N., Gau, M., and Stieger, D. (2018). Design principles for sensemaking support systems in environmental sustainability transformations. European Journal of Information Systems 27(2), 221-247. https://doi.org/10.1057/s41303-017-0039-0

Sevaldson, B. (n.d.). An introduction to Systems Oriented Design. Retrieved from http://www.systemsorienteddesign.net/index.php/sod/nutshell

Shrivastava, P., Stafford Smith, M., O'Brien, K., and Zsolnai, L. (2020). Transforming sustainability science to generate positive social and environmental change globally. One Earth, 2(4), 329-340. https://doi.org/10.1016/i.oneear.2020.04.010

Staricoff, R., L. (2004). Arts in health: A review of the medical literature. Arts Council England. http://www.creativenz.govt.nz/assets/ckeditor/attachments/1030/staricoff $\mathrm{r}$ arts in health.pdf ?1410235845

Stuckey, H. L., and Nobel, J. (2010). The connection between art, healing, and public health: a review of current literature. American journal of public health, 100(2), 254-263. https://doi.org/10.2105/AJPH.2008.156497 
Swain, R. .B. (2018). A critical analysis of the sustainable development goals. In Leal W. Filho (Ed..) Handbook of sustainability science and research. World sustainability series. Springer. https://doi.org/10.1007/978-3$\underline{319-63007-6 \quad 20}$

Tai, J. (June 16, 2020). 8 in 10 Singaporeans willing to pay more for essential services. https://www.straitstimes.com Lsingapore/manpower/8-in-10-singaporeans-willing-to-pay-more-for-essential-services

UNESCO. (2018). Reshaping cultural policies: Advancing creativity for advancement. https://unesdoc.unesco.org/ark: /48223/pf0000260592/PDF/260592eng.pdf.multi

United Nations. (July 2016). Global sustainable development report 2016. https://sustainabledevelopment.un.org Lcontent/documents $/ 2328$ Global $\% 20$ Sustainable $\% 20$ development $\% 20$ report $\% 202016 \% 20$ (final). pdf

United Nations Conference on Trade and Development. (January 2019). Global creative economy shows resilience, growth - report. https://unctad.org/news/global-creative-economy-shows-resilience-growth-report

United Nations Conference on Trade and Development. (n.d.). Creative economy programme and network. https://unctad.org/topic/trade-analysis/creative-economy-programme/creative-economynetwork

United Nations Department of Economic and Social Affairs. (n.d.). Transforming our world: The 2030 agenda for sustainable development. https://sdgs.un.org/2030agenda

United Nations Environment Program. (2019). Summary for policymakers. Global resource outlook 2019. Natural resources for the future we want. https://www.un.org/en/land-natural-resources-conflict/pdfs/ GN Extractive.pdf

Van der Linden, S., Maibach, E., and Leiserowitz, A. (2015) Climate Change Psychology: Five Insights. Yale program on climate change communication. https://climatecommunication.yale.edu/publications/fivepsychology-insights-to-engage-the-public/

Vermeulen, M. and Maas, K. (2021). Building legitimacy and learning lessons: A framework for cultural organizations to manage and measure the social impact of their activities. The Journal of Arts Management, Law, and Society. 51. 1-16. https://doi.org/10.1080/10632921.2020.1851839

Voices of Culture. (February 2021). Brainstorming report. Culture and the united nations sustainable development goals: Challenges and opportunities. https://voicesofculture.eu/wp-content/uploads/2021/02/VoCBrainstorming-Report-Culture-and-SDGs.pdf

Waddell, S. (November 12, 2015). Action research and large systems change. [YouTube]. https://www.youtube.com/watch?v=idKAUFfWhg0

Wapner, P and Elver, H. (Eds.). (2016). Reimagining climate change . Routledge.

Weldon, W. 1972. Why creativity? An analogy to the economics of supply and demand. The Journal of Creative Behavior, 6, 55-60. https://doi.org/10.1002/i.2162-6057.1972.tb00908.x

World Economic Forum. (2021). The global risks report 2021. 16th edition. Insight report. http://www3.weforum.org/docs/WEF The Global Risks Report 2021.pdf

Yusoff, K. and Gabrys, J. (2011). Climate change and the imagination. WIREs Climate Change, (2) 516-534. https://doi.org/10.1002/wcc.117 